TRAMES, 2009, 13(63/58), 1, 14-40

\title{
ON THE SIMILARITY AND DISTINGUISHABILITY OF HUMOUR AND FIGURATIVE SPEECH
}

\author{
Arvo Krikmann \\ Estonian Literary Museum, Tartu
}

\begin{abstract}
The article aims to discuss the relationships between (verbal) humour and figurative speech, primarily focusing on the current theoretical dispute between the representatives of the 'classical' linguistic theories of humour (particularly Salvatore Attardo) and the younger generation of cognitive linguists (Kurt Feyaerts, Gert Brône, Tony Veale), and some contemporary psycholinguistic achievements (particularly Rachel Giora). The main conclusions suggested by the present state of the research are: (1) The cognitive similarity between metaphor and verbal humour is easy to recognize, but it is difficult to devise clear-cut theoretical criteria to distinguish between the two. (2) Considering the conceptual structure (interpretation, 'construal') of a narrower area, the following rule of thumb seems to hold: of the two incompatible scripts ( schemas $\sim$ frames $\sim$ isotopies) involved in both metaphor and punchlined joke in the case of metaphor the first (overt, redundant) script 'wins', but in the case of joke the second (hidden, informative) prevails. (3) As the same conceptual tools are applicable to explain the perception of both funniness and figurativeness, these perceptions are definitely not discrete or exclusive, but continuous and gradual. To come closer to an 'ecologically valid' means of distinguishing between them, the cognitive theory should perhaps pursue a closer integration with researchers of the cultural and social aspects of human communication.
\end{abstract}

DOI: $10.3176 /$ tr.2009.1.02

Keywords: figurative speech, metaphor, metonymy, humour, joke, punch line, resolution, incongruity, script, schema, blend(ing)

\section{Introduction (content map)}

Section 2 below reveals the essence of the cognitive similarity between metaphor and humour (particularly the punchlined joke): both of these are embodied in texts with dual planes of meaning, both involve a semantic contradiction / incompatibility that the recipient has to disambiguate, using his/her linguistic competence and encyclopaedic knowledge to find some analogy or other 'common 
link' to relate the involved planes of meaning. This idea originates from Aristotle. Further, two important attempts made in the 1960s to embed the units with twofold planes of meaning into certain broader supersystems are briefly summarized. One of these is Arthur Koestler's tract The Act of Creation (1964) about the three main forms of creativity - humour, discovery and art, each displaying a specific type of bisociation bisociativity between the two frames of reference (worlds of discourse). Another is The Structural Semantics (1966) by Algirdas Julien Greimas, the basic concept of his theory being the notion of isotopy, which means different 'readings' of ambiguous expressions, for which Greimas aims to develop a unified procedure of semantic disambiguation.

Section 3 seeks to give a brief general overview of the recent history of research in both areas and the process of becoming conscious of one another. Three early seminal, but now largely abandoned works by I. A. Richards (1936), Roman Jakobson (1956) and Max Black (1962) are recalled. I also outline the development of attempts to cope with metaphor as a violation of certain rules (selection restrictions, distribution rules, conversational maxims) in postChomskian semantics (Jerrold Katz, Jerry Fodor, Paul Postal, Uriel Weinreich, Paul Baumgärtner, Theun van Dijk, Samuel R. Levin) and Gricean pragmatics, and the epochal shift to the cognitivistic paradigm George Lakoff and Mark Johnson brought about with their book Metaphors We Live By (1980), soon followed by works by other outstanding cognitivists, such as Mark Turner (later in collaboration with Gilles Fauconnier), Eve Sweetser, Bipin Indurkhya, Zoltán Kövecses et al. The basic ideas and terms used in the cognitive theory of metaphor and metonymy are briefly listed: conceptual metaphors as fundamental tools humans use to conceptualize their world picture and everyday experiences; the concepts projection and mapping; conceptual domains, (image) schemas, scripts, frames, mental spaces, etc. In addition, the contribution of psychology to the two research areas is addressed: the Incongruity - Resolution Theory of Humour introduced in the 1970s by psychologists Jerry M. Suls and Thomas R. Shultz, and its impact on the later theories of verbal humour proposed by Raskin and Attardo (SSTH and GTVH); Amos Tversky and Andrew Ortony with their ideas of the salience, imbalance, asymmetricity and irreversibility of metaphors and similes; Tourangeau and Sternberg with their theory of the domain-related aptness of metaphors; the main clusters of problems concerning figurative speech (particularly idioms) in contemporary psycholinguistics.

Section 4 constitutes the baricentre of the article. Firstly, the obscurity and ambivalence of many basic concepts is touched upon, with corroborating examples being provided about radically different conceptualizations of the terms opposition, resolution, domain, aptness vs. funniness etc. in the works of different authors or a particular author at different times. Secondly, the violation of Gricean maxims in jokes is addressed: Attardo's polemic with Victor Raskin's theory about joke-telling as a kind of non-bona-fide communication and specific secondary 'joke-oriented' modifications of maxims, and with Haruhiko Yamaguchi around the question of 'who is guilty' for maxim violations in jokes, 
etc. Thirdly, the section handles criticism that the traditional script-based linguistic theories of humour (SSTH and GTVH) have received from the younger generation of cognitive linguists (Kurt Feyaerts, Geert Brône, Tony Veale et al.) and Attardo's self-defensive vigorous counter-criticism. The author's opinion coincides with Attardo's view that the newcomers from cognitive linguistics often fail to acknowledge the cognitive specificity of humour, tend to reduce analysis of humorous phenomena to properties that humour shares with non-humorous forms of human communication, the novelty of their approaches consisting in simply translating propositions from one terminological system to another. Among hitherto unused resources Feyaerts and Brône mention, for example, Rachel Giora's Marked Informativeness Requirement and Optimal Innovation Hypothesis, and Ronald Langacker's definition of metonymy; they analyze some German metonymical phraseologisms and claim that the difficulty of processing them is measurable via the number of causal 'steps' that are necessary to reach the target concept that the metonymy is to stand for. Another conceptual tool that cognitive linguists consider to be fruitful for humour analyses is blend(ing), introduced by Turner and Fauconnier: as an example, we provide Seana Coulson's analysis of the cartoon by Jeff MacNelly, "William Washington Clinton". The cognitivist proposals undoubtedly prove the idea of the continuity and proximity of various forms of creative use of human cognitive capabilities, but are of little help in distinguishing humour from figurative speech.

In Section 5, the principal cognitive difference between metaphor and punchlined jokes is hypothesized: in metaphors the target / the first (overt, redundant) script 'wins', but in jokes the source / the second (hidden, informative) script 'wins'. That is, a (fresh) metaphor crosses the border, reaches the obstacle, backtracks to the left, looks around, returns to the right, takes something along and returns to the left; the joke crosses the border, reaches the obstacle, backtracks to the left, looks around, takes something along, returns to the right and remains. The hypothesis is paralleled with some earlier observations by Hillson and Martin, Pollio, and particularly Rachel Giora.

In the final Section 6, the chances for solving the border problems between humour and figurative speech on purely cognitive grounds are called into question, and humour scholars are invited to strive for closer integration with researchers of the cultural and social aspects of human communication, also reconsidering the former theories of superiority/disparagement and relaxation/relief that have been declared tacitly obsolete and seek to discover the deeper collaborative drives of humour processes that Tony Veale has called 'social logic'.

\section{Humour and metaphor involve two planes of meaning}

The deep cognitive similarity between metaphor and humour (particularly the punchlined joke as its prototypical representative) is easy to recognize, and this has actually long been noticed and discussed by numerous philosophers, psycho- 
logists, linguists and others. Both metaphor and humour are embodied in texts with two planes of meaning. When a recipient encounters such a text for the first time, he/she encounters a semantic contradiction (inconsistency, incompatibility, ambiguity) and feels a need for it to be disambiguated (conceptualized, interpreted, construed) via certain semantic alterations using his/her linguistic competence and encyclopaedic knowledge. To succeed in this, a certain intersection (similarity, analogy, ambiguous element, causal link, inferential chain, etc.) must be found between the two planes of meaning.

This idea is actually very old, and originates from Aristotle. Of the four kinds of metaphor in Aristotle's Poetics, only the fourth (the analogy) coincides with the contemporary concept of metaphor, viz. the notoriously quoted locus from Chapter 21:

Analogy or proportion is when the second term is to the first as the fourth to the third. We may then use the fourth for the second, or the second for the fourth. Sometimes too we qualify the metaphor by adding the term to which the proper word is relative. Thus the cup is to Dionysus as the shield to Ares.

The cup may, therefore, be called 'the shield of Dionysus,' and the shield 'the cup of Ares.' Or, again, as old age is to life, so is evening to day. Evening may therefore be called, 'the old age of the day,' and old age, 'the evening of life,' or, in the phrase of Empedocles, 'life's setting sun.'

Aristotle's views on humour admittedly remain in the lost part of his Poetics. However, considering some of his remarks emphasising the importance of surprise in the rhetorical influence of humour, John Morreall (1987: 14) has been so bold as to call Aristotle the forefather of incongruity theories of humour.

In the 1960s two significant attempts were made to embed the units with twofold planes of meaning, including humour and figurative speech, into certain broader supersystems.

One of these is Arthur Koestler's tract The Act of Creation (1964) about the forms of creativity. To Koestler's mind, the fundamental forms of the revelation of creativity constitute a kind of triptych - humour, discovery and art. All of these are founded on bisociation $\sim$ bisociativity, i.e. the specific, conceptually 'two-planed' nature of any creative act. In the case of humour, this means a comic collision of or oscillation between two frames of reference / worlds of discourse / codes / associative contexts; in the case of scientific discovery - objective analogy, and in the case of art - the image. Each kind has its own specific "emotional mood": aggressive in the case of humour, neutral in the case of discovery, and sympathetic, admiring or tragic in the case of art.

Another noteworthy work is Sémantique structurale by Algirdas Julien Greimas (1971 [1966]). Greimas's interests are not specifically focused on the theory of humour or the theory of figurative speech, but on establishing a deductive theory of general semantics. One of the basic concepts of that theory is the notion of isotopy, which means, roughly speaking, different 'readings' of ambiguous expressions, for which Greimas aims to develop a unified procedure of semantic disambiguation wherever necessary, be it for ordinary language, meta- 
phoric language or humour. In the end, Greimas' theory was not deeply fertilizing for either metaphor or humour theory, although he has undoubtedly remained a classic for semioticians. Among the examples of his isotopies, however, one can find the following joke (Greimas 1971 [1966]: 61 < Point de vue, 23 févr.1962):

C'ést une brillante soirée mondaine, trés chic, avec des invités triés sur le volet. À un moment, deux convives vont prendre un peu l'air sur la terrasse:

- Ah! fait l'un d'un ton satisfait, belle soirée, hein? Repas magnifique...et puis jolies toilettes, hein? - Ça, dit l'autre, je n'en sais rien.

- Comment ça?

- Non, je n'y suis pas allé!

This has prompted several researchers (especially in Europe) of jokes and narratives in general to use Greimas's conceptual tools for the analysis of supersentential semantically cohesive texts (see e.g. Attardo 1994:62-107, Attardo et al. 1994:27). The shift from one isotopy to another seems, once again, to be obviously synonymous with the concepts and patterns used by other contemporary and later authors when speaking about humour or metaphor, like Koestler's clash of the two bisociated planes of meaning, or Raskin's (1985) transition from one intersecting or opposed script to another, or Coulson's semantic leaps and frameshifting (e.g. Coulson 1997, 2001, Coulson and Kutas 1998 and numerous later works).

For example, Raskin's favourite object of numerous quotations and profound analysis (see e.g. 1985:32, 82-85, 99-100, 104-105, 117-127 and elsewhere, as well as in later writings by other authors) is the joke about the 'bronchial patient':

"Is the doctor at home?" the patient asked in his bronchial whisper. "No," the doctor's young and pretty wife whispered in reply. "Come right in."

After Raskin, here the scripts of DOCTOR (or more precisely, that of PATIENT) and LOVER are opposed. The interpretation of the joke begins in the spirit of the first script, but the punch line utterance whispered by the doctor's young and pretty wife introduces content elements incompatible with the fist, medical script, and therefore the recipient has to (and certainly will) find another suitable script - the script of LOVER - to eliminate the inconsistency and restore the semantic coherence of the text.

\section{Some comments on recent history}

Despite early works by Koestler and Greimas, the theories of metaphor and humour had a long way to go before they discovered each other's existence and substantial commonalities were discovered in their topics of research. Even recently, Gert Brône, Kurt Feyaerts, and Tony Veale (2006: 209), the prominent instigators of attacks on Victor Raskin's and Salvatore Attardo's theories of humour (known as SSTH and GTVH) from the part of the 'new wave' of cognitive linguists, seem to consider humour scholars to be more guilty in this. (Cf. also Attardo's vigorous retort ibidem (2006:345).) 
Metaphor, as well as metonymy, simile, personification, etc., were traditionally considered as tropes and thought to belong primarily to literature and poetry. Traditional readers and dictionaries have defined metaphor as the substitution of one word for another on the basis of similarity, and metonymy as their substitution on the basis of contiguity.

There are three important early contributions to the theory of metaphor that have now become relatively abandoned (despite writings by Douglass 2000), Dirven 2002 [1993] and some others), but have had a strong actual interdisciplinary impact on the later research. I. A. Richards (1936) bequeathed to his successors the terms tenor and vehicle to denote the basic components of metaphor, as well as the idea of tensional interaction between the two, which was later developed by Max Black (1962). Roman Jakobson (1956), proceeding from two opposite types of aphasia, created the distinctive criterion between metaphor and metonymy (i.e. similarity / contiguity) two-dimensional, adding the syntactic or positional axis to the previous semantic one, and thus relating metaphor with the paradigmatic and metonymy with the syntagmatic 'pole' of language.

In Chomskian generative linguistics, metaphor long remained an enfant terrible; it was regarded as a language error, a violation of selection restrictions or distribution rules. Thereby metaphor became, at the same time, one of the pressure factors that prompted linguists to shift the focus of their interests from syntax to semantics, and further to pragmatics. In Gricean pragmatics (see e.g. 1991 [1989]: 33), however, the phenomena of figurative speech (metonymic quasi-tautologies, metaphors, irony, hyperbole and litotes) are handled as flouting forms of violations of conversational maxims, and in Searlean speech act pragmatics (see e.g. 1979), the understanding of metaphors is considered to be a reconstruction of the truth conditions for metaphorical utterances. In the works of Jerrold Katz, Jerry Fodor, Paul Postal, Uriel Weinreich, Paul Baumgärtner, Theun van Dijk and others, various tools are proposed to make metaphor accessible for linguistic description. The Semantics of Metaphor by Samuel R. Levin (1977) is perhaps a kind of peak and quintessence of these 'purely semantic' efforts that lasted until the need for involving the notorious 'encyclopaedic knowledge' had become absolutely evident and George Lakoff became decisively bored of 'manipulating meaningless symbols'.

The forthcoming change in paradigms is predictable already from Metaphor and Thought edited by Andrew Ortony (1979). The first, now extensively quoted book by Lakoff and Johnson (1980), which was entirely dedicated to the metaphor, brought about an explosive outburst of interest and research of metaphor (among other earlier books are, e.g., Johnson 1987, 1993, Turner 1987, 1991, 1996, Lakoff (and Kövecses) 1987, Lakoff and Turner 1989, Sweetser 1990, Indurkhya 1992, Kövecses 1986, 1988, 1990). In Lakoffian theory metaphor and metonymy are not simply operations of substituting or transfer involving the meanings of single words, nor are they tropes, but basically conceptual metaphors, i.e. fundamental tools which human beings use day after day to conceptualize and categorize certain 'less clearly delineated' parts of their world picture in terms of 
'more clearly delineated' parts, a certain operation of projection, or mapping between two 'somethings'. There are two kinds of such mental 'somethings' bigger and smaller. Bigger ones are called conceptual or experiential domains, and inside them are smaller ones called (image) schemas, scripts, frames; in the later, conceptual integration and blending era, dominated by Gilles Fauconnier and Mark Turner, also mental spaces. In the Lakoffian theory, metaphor is the A IS B operation relating two different domains, and metonymy is the A STANDS FOR B (or more precisely: B STANDS FOR A) relation within one and the same domain. The Lakoffian terminological counterparts for Richards' tenor and vehicle are target and source.

In psychology the turn to humour happened earlier than to metaphor. By the beginning of the 1970s the former theories of superiority $\sim$ disparagement aggression and release $\sim$ relief seemed to have exhausted their possibilities, and Jerry M. Suls (see e.g. 1972), Thomas R. Shultz (see e.g. 1996 [1976]) and others, proceeding from the ideas of incongruity (contradiction, inconsistency) found in the earlier theories, introduced their Incongruity - Resolution Theory (IRT). Its essence, summarized in Suls' problem-solving terms, is the following (Suls 1972:82):

... a joke or cartoon is found to be funny as the result of a two-stage process. In the first stage, the perceiver finds his expectations about the text disconfirmed by the ending of the joke or, in the case of a cartoon, his expectations disconfirmed by the caption. In other words, the recipient encounters an incongruity - the punch line. In the second stage, the perceiver engages in a form of problem solving to find a cognitive rule which makes the punch line follow from the main part of the joke and reconciles the incongruous parts. A cognitive rule is defined as a logical proposition, a definition, or a fact of experience. The retrieval of such information of such information makes it possible to reconcile the incongruous parts of joke.

The IRT called into being a flow of experimental research in psychology and psycholinguistics with the aim of testing the validity and specifying the nature of the concepts of incongruity and resolution, by observing the funniness ratings of various humorous items (jokes, cartoons, etc.) in various presets of conditions. (I will refer below only to some writings of the kind that are ineluctably necessary in the present context.)

The now best-known and increasingly debatable theories of verbal humour proposed by Raskin and Attardo (SSTH and GTVH), though announced by their creators as strictly linguistic, actually also have much in common with the ideology and conceptual apparatus of psychological IR models. Another most extended linguistic theory by Graeme Richie (2003, based on the bulky former research) is computer-processing-oriented and includes chapter after chapter of severe criticism on the theoretical foundations of both the IR and SSTH / GTVH models.

Lakoffian theory primarily addressed the inventory and internal structure of the conceptual-metaphorical world itself, and not the processes of comprehension 
of figurative speech in actual verbal communication. This gap was left for psychology and psycholinguistics to fill. When psychology met metaphor and figurative speech in general, Eleanor Rosch had already published her first works on prototypicality, the basic level of human 'natural categorizations', etc. The principal importers of metaphorical topics to psychology were Amos Tversky (see e.g. 1977) and Andrew Ortony (e.g. 1979), with their ideas of the salience, imbalance, asymmetricity and irreversibility of metaphors and similes, and Tourangeau and Sternberg (e.g. 1981, 1982), with their theory of domain-related aptness of metaphors - that is, in order to constitute an apt metaphor, its constituents must have an optimally long semantic distance between domains, and engage possibly similar within-domain positions.

It is impossible, within the limits of this paper, to give any general account of the huge and branching experimental research into various kinds of figurative language (including metaphors and metonymies, idioms, proverbs, irony, etc.), based on the measuring of reading times or the manipulation of the sets of empirical rating data for various expectedly valid but semantically undefined features of text items, and proceeding empirical data via regression, factor or other multidimensional analyses, Shannon's formula for quantifying information $v s$. entropy or other statistical tricks, in order to convert them to a lesser number of generic features like Osgood's 'Evaluation-Potency-Activity' in the output. Sometimes the number of simultaneously ratable features is astonishingly great for example, comprehensibility, poeticality, appropriateness, beauty, formality, political tastefulness and precision (see e.g. Steen 1994, Utsumi 2005, 2006b).

The discussion of the last decades has addressed, among others, the following aspects or problems:

1) the role and function in the process and result of interpreting figurative speech, of factors such as

a) language-related storages in (semantic and episodic) memory: their structure (e.g., whether or not idioms are stored like 'long words'), conceptual and lexical relationships, strength relations;

b) the contextual surroundings of the given word, expression, sentence or longer text: present or absent, verbal or situative, long or short, literal or figurative, neutral or priming;

2) into which stages can the process of understanding of the figurative expression be divided, and which stages and at which preconditions (e.g. in the case of entrenched / innovative metaphors or idioms) must be passed (e.g. which meanings retrieved) or can be bypassed;

3) what is, at different preconditions, the final mental result of the understanding process, which elements of meaning activated in the course of mental work will be cancelled, suppressed, or retained.

Some directions of research seem to be notably related to and influenced by ideas bred in cognitive linguistics, for example the long dispute over the two eventual functions of metaphor ('comparative' or similarities-ascertaining vs. 'predicative' or categories-creating) between the teams of Dedre Gentner and Sam 
Glucksberg (see e.g. Gentner and Medina 1997, 1998, Gentner and Namy 1999, Gentner and Wolff 2000, Gentner et al. 2001, Markman and Gentner 2000, Bowdle and Gentner 2005 and others / Glucksberg 2001 and others), or likely corroborating the blending theory view of abundant so-called emergent features (e.g. Becker 1997, Gineste, Indurkhya and Scart 2000); cf. also the freshest, computerised approach to both topics by Akira Utsumi (2006a, 2005).

To return later to the distinguishability of humour (prototypically: jokes) and figurative speech (prototypically, metaphor), we briefly decompose our problem into two different sub-problems:

1) humour vs. non-humour $\sim$ funniness vs. non-funniness

2) humour vs. figurative speech.

\section{The factor of processing difficulty}

\subsection{Problems with conceptualization and terminology}

Many proponents of IR theories seem to assume that incongruity and resolution intrinsically provide the necessary and sufficient conditions to regard a text or any other object as funny, i.e. to conceptualize the essence of our humorous impressions. But what is the precise meaning of the term opposition, used by Raskin, Attardo and others to characterize the relationship of the incongruous elements of the joke? What do Lyons' local antonyms, or Ziv's local logic, or Aubouin's justification, used to specify the meaning of that opposition, exactly mean? (Cf. passim in Raskin 1985, Attardo and Raskin 1991). Ritchie (2004 passim, e.g.: 16, 50, $61 \mathrm{ff}$., and elsewhere) suggests replacing incongruity and resolution with a more analytical set of conditions (static-inherent, static-presentational, dynamic-inherent, and dynamic-presentational) and terms (OBVIOUSNESS, CONFLICT, COMPATIBILITY, CONTRAST, INAPPROPRIATENESS), also distinguish jokehood from funniness. The enhancing effects resulting from these changes hardly become evident to people who are not familiar with the AI developments of joke analysis and its purposes.

The existing literature offers drastic examples of how differently one and the same researcher at different stages of his development, or two researchers with different theoretical backgrounds, can conceptualize one and the same term.

Take, for example, the concept of resolution. Attardo (1997) introduces his Setup-Incongruity-Resolution model (SIR) that aims to relate his basic model of verbal humour (GTVH) using traditional IR approaches (and indirectly also with his linear Isotopy-Disjunction Model of jokes, or IDM (see Attardo 1994: Ch.2, Attardo et al. 1994)). He finds the setup phase of the SIR to correspond to the script overlap (i.e. the connector in the IDM model), the incongruity phase to the script opposition (SO) component of the GTVH (i.e. disjunctor in the IDM), and the resolution phase to the logical mechanism (LM) component of the GTVH. As to the last assignment, Attardo makes a special accentuating comment: "It should be noted that I am claiming that the LM is the resolution itself, not just an enabling mechanism thereof" (1997:409). 
This linkage is somewhat surprising as a whole, because the GTVH model in its initial version (see e.g. Attardo and Raskin 1991, Attardo 1994:222 ff.) was a linear array of hierarchically ordered (weighted) properties of texts that were related with various 'knowledge resources' and intended to serve as criteria for measuring the degree of similarity / dissimilarity between joke texts, the LA (Language) being the weakest and the SO the strongest distinctor. The classic IR model, on the contrary, is obviously a linear description of how a joke is received and understood. Nevertheless, the (inferential, or 'metonymic') relatedness of the SOs with incongruity appears natural and well-grounded, but ultimately bizarre in the case of LM and resolution, because LM is the only component of the GTVH that lacks any textual 'counterpart'. Ritchie (2004:74), like many others before and after him, is puzzled about the functionality of LMs in the GTVH and asks: "...where is its formal role in the framework? In particular, does the assignment of a particular LM describe how the two scripts are related, indicate what is odd about the events described in the resulting interpretation (script) or state how the scripts (or other information) are conveyed by the text?" Considering the meaning(s) of resolution in original IR-models, LMs in Attardo's SIR model should now describe the inner mental work used to find a suitable 'cognitive rule' to come up with the correct final interpretation. Considering the list of LMs provided in Attardo et al. 2002, this should instead lead to certain scholarly categorizing meta-judgements about the involved cognitive 'tricks of joke-making'. Considering the general nature and purpose of the original GTVH model, this would deepen distrust in the alleged monotonously hierarchical structure of the joke repertoire.

Hillson and Martin (1994), in turn, have made an attempt to associate the incongruity-resolution approach with the idea of between- and within-domain relationships introduced by Tourangeau and Sternberg. Such a combined model was applied to a set of expressions with the 'absent fourth', viz. of the form $A$ is the $B$ of $C$, where $A$ is the first individual, $B$ is the second individual, and $C$ denotes the domain of $A$, e.g. Saddam Hussein is a buzzard of world leaders. The between-domain semantic (expectedly long) distances were taken as a measure of incongruity (i.e. dissimilarity) and within-domain (expectedly short) distances as a measure of resolution (i.e. similarity). One and the same set of ABC-form sentences underwent two experiments, being treated as metaphors (and rated for aptness) or jokes (and rated for funniness), respectively - cf. also here below, Section 4. The results of the humour experiment were briefly summarized for general and extreme cases separately: 1) “... as predicted, jokes were rated as more humorous if there was greater between-domain semantic distance between their concepts, which we conceptualized as a measure of incongruity. In contrast, the correlation between mean humor ratings and within-domain distance was nonsignificant" (p. 15); 2) "As predicted, the jokes with the highest mean ratings of humor were those with a high between-domain distance (high incongruity) and a low within-domain distance (high resolution)" (p. 16). 
So far, so good. Each of the three above conceptualizations of the term resolution, taken separately - the final part of joke reception, looking for and finding the 'cognitive rule', or 'second script' / logical mechanism / measure of withindomain distance, i.e. similarity - is in a sense reasonable, but they are very difficult to melt together in any acceptable logical way.

To be objective, incongruity and resolution are no more vague and fuzzy than the concepts used in 'figurative speech linguistics', such as domain, image schema, idealized cognitive model, etc. The meaning of the term domain, for example, varies drastically in the works of various authors, from simply 'concepts' to 'the most abstract categories as 'intersecting dimensions, or aspects, of everything', like Time, Space, Causality, etc.)', to 'different stages of the Great Chain of Being, like Inanimate objects / Plants / Animals / Humans / Supernatural beings'. Or, for instance, take the problem of the compatibility of the domainrelated concepts of mapping and projection with the alleged STANDS FOR quality of metonymy. In their first book, Lakoff and Johnson (1980: 36) cautiously state: "Metaphor is principally a way of conceiving of one thing in terms of another, and its primary function is understanding. Metonymy, on the other hand, has primarily a referential function, that is, it allows us to use one entity to stand for another". However, since the later writings (for the very first time, perhaps, Lakoff and Turner 1989:103) have also happened to apply the notion of mapping to metonymy, too, the still later writings were propelled, in order to speak about the 'standing for' relation within one and the same domain, to invent rescuing terms, such as matrix domain, domain matrix, subdomain, etc. (see e.g. Barcelona 2000:32-33, 2003:89 ff., Ruiz de Mendoza and Hernández 2001:324 ff., Radden and Kövecses 1999, Peirsman and Geeraerts 2006, for discussion).

Experiments with the rating of multiple features (cf. above about Steen and Utsumi) inevitably turn out to be simultaneous explorations of the funniness of certain object texts, as well as tacit explorations of the semantics of the used metaterms themselves, i.e. another version of the notorious use of one and the same entity as the object and device of the research. Any metalinguistic verbalizations used to convey the internal mental, non-verbal processes inevitably turn out to be inadequate and conditional in a sense. Attardo, Ritchie and others also argue over the falsifiability of humour theories, as Gibbs (2000: 349) accuses the theory of conceptual integration of having a post hoc quality and unfalsifiability - it is hard to conceive what the falsifiability of such kind of 'impressionistic', inexact theories should mean and in what way it could be operationalized. Nevertheless, they are, at the present moment, the only possible way to systematize knowledge and speak of such highly complicated matters as humour or figurative speech.

\subsection{Humour and figurative speech violate Gricean pragmatic maxims}

One of the recent issues of Journal of Pragmatics 35, 9 (2003), was completely dedicated to the pragmatics of humour, although altogether bypassing the problem of maxim violations in humour. Grice himself (see e.g. 1991 [1989]:33) qualifies all basic kinds of figurative speech as flouting maxims: irony, metaphor, hyper- 
bole and litote violate the Maxim of Quality, quasi-tautologies (Boys are boys; Women are women; War is war), by some other authors (e.g. Gibbs 1994: 345351) also related to metonymy, violate the Maxim of Quantity, and so on. Raskin (1985:100-104) considers joke-telling to be a kind of non-bona-fide communication. The speaker can produce humour spontaneously or intentionally, and the audience can expect or not expect joking. Due to the need for switch-over, some interferences can happen in the initial phase of joke-telling, but when the switchover to the 'joke wave' is done, the Cooperative Principle begins to operate again, though in a specific 'joke-oriented' manner and with modified maxims, e.g. "Give exactly as much information as is necessary for the joke", instead of the usual Maxim of Quantity, "Say only what is compatible with the world of the joke", instead of the usual Maxim of Quality, etc.

Attardo (1993; 1994:271-292) presents the problem of maxims as a paradox: jokes seem to violate maxims so abundantly that "the claim that all jokes involve the violation of (at least) one maxim of the $\mathrm{CP}$ is commonplace in humor research" (1993:541), but may, at the same time, be understood with amazing ease and speed. Prompted by the paper by Haruhiko Yamaguchi (1988), who had sought to solve the maxim paradox with the aid of the mention theory proposed by Dan Sperber and Deirdre Wilson (1981), this implies answering the question 'who is guilty?', that is, responsible for, maxim violations. Yamaguchi claims that the speaker delegates the responsibility for the violations 'inside the joke', to some character(s) of the narrative, Attardo, on the contrary, judges firmly: "The narrator is always guilty of violation of the C[ooperative] $\mathrm{P}$ [rinciple]: either because he/she directly violates one of the maxims or because he/she indirectly does so by not exposing the violation of which he/she is aware" (1993:547-548, 1994:282-283).

Attardo's attitude to Raskin's views on the pragmatics of jokes is drastically different in the works of (1993) and (1994) - severely critical in the former and notably mild in the latter. In (1993), for example, Raskin allegedly cuts through any connections between the 'secondary' (joke level, non-bona-fide) and 'primary' bona-fide communication, overestimates the role of specific 'contextual clues' that prime the transition from the usual to humorous type of communication, and so on. I cannot determine the exact reasons for the change. Anyway, in some of his (inaccessible to me) papers from 1992, Raskin appears to have reconsidered his former conception and then speaks of a multilevel, hierarchically structured and interactive system of CPs - cf. Attardo's (1994:286-287) positive comment about them. In any case, Attardo has now obtained a considerably broader and more mature perspective on CP matters: "It seems also that a radical dichotomy between 'serious' BF [= bona-fide-] use of language and 'humorous' NBF [= non-bonafide-] cannot be maintained in reality. Grice's hypothesized speaker, totally committed to the truth and relevance of his/her utterances, is a useful abstraction, but should be considered only as such. In reality, speakers engaged in everyday communication use humorous remarks that hearers decode, interpret as such, and use along with other information to build their vision of the communicative context" (ibidem, p. 287). 
This broader and more flexible 'polytomic' view, which affirms the multidimensional, multilevel, multipurpose and flexible nature of human communication, relativises its criteria of cooperation and thresholds between its 'ordinary' and 'secondary' types, thus being neatly congenial with contemporary trends in the humanities.

However, to return to the basics, it does not allow us to distinguish more precisely which violations of maxims will simply result as communicative errors, which ones as units of figurative speech, and which ones as humorous items.

\subsection{Cognitive-linguistic invasion in the kingdom of humour theory}

In the last few years, the traditional script-based linguistic theories of humour (SSTH and GTVH) have undergone increasingly stronger attacks from both the 'non-script-spirited' traditionalists and the younger generation of cognitive linguists. At least two recent issues of the journal HUMOR, 17-4 (2004) and 19-3 (2006) have been almost entirely dedicated to that criticism, with unfortunate LMs its constant and favourite target.

The latter issue also includes an extensive introductory paper by Geert Brône, Kurt Feyaerts and Tony Veale (Brône et al. 2006) which provides some politically correct notes on the principal shortcomings of the SSTH and GTVH; calls upon humour scholars and cognitive linguists to make efforts to establish closer collaboration, thus bringing new and fascinating and increasingly complicated phenomena of creative language within reach of their scientific capabilities; lists the abundant conceptual and thematic contribution cognitive linguistics and pragmatics can make to that partnership (salience, conceptual metaphor, metonymy, viewpoint, prototypicality, mental spaces, frame-shifting, usage-based models); describes mutual benefits that could be acquired; delineates some perspectives and directions for further research. In general, however, the stance tends to obtain a somewhat asymmetrical 'fish from you, hook from us' form, with the humour side being assigned mainly the role of a supplier of raw material, and not of theory.

The issue ends with vigorous feedback and opposition from Attardo (2006). Attardo, substantially, does not admit any reproaches made towards the SSTH and GTVH. I do not aim to reiterate here my own remarks (made elsewhere) on these models (Krikmann 2007). In my opinion what perfectly coincides with Attardo's view is that the (brave and wild, generally) newcomers from cognitive linguistics very often do not assign humour its own 'level of existence' or identity among other forms of creative use of our (verbal or non-verbal) cognitive capabilities, fail to acknowledge the cognitive specificity of humour, tend to reduce analysis of humorous phenomena to properties that humour shares with non-humorous (creative or not) forms of human communication for which cognitive linguistics has already elaborated appropriate tools for processing. Time and again the novelty proves to consist just in translating propositions from one terminological system to another, and as a result is, in Attardo's (2006:341) words, "merely a notational variant of previously available analyses". Let us quote Attardo (2006: 344) once more: 
There's hardly anything to fault to the claim that humor interpretation involves "complex inferential activity," except, of course, that so does pretty much any non-trivial textual interpretation and so humor is not special in this respect. In other words: this may be fascinating news for any number of linguists or cognitive scientists, but it is essentially irrelevant for humor theorists. Humorous interpretation uses the same linguistic/cognitive tools as nonhumorous interpretation does. So what? What is interesting is how humorous discourse differs from serious discourse.

\subsubsection{Hopes based on metonymy}

Kurt Feyaerts and Geert Brône (Brône and Feyaerts 2003, 2004: 364-372, cf. also Brône et al. 2006) complain that the existent script-based models of humour have so far utilized only an insignificant part of the theoretical results gained and methodical devices used in cognitive linguistics and cognitive linguists, on the other hand, have not been very interested in humorous matters.

Among hitherto unused resources they list, for example:

1) several operations of construal addressed by William Croft and D. Alan Cruse (e.g. 2004);

2) Rachel Giora's Marked Informativeness Requirement, that is, the amount of information retrieved and inferred to make the punch line understandable, must be remarkably big, and Optimal Innovation Hypothesis, that is, the figurative and humorous items are most enjoyable if they convey a balanced share of salient and innovative, marked information (1991 and 2003:176-184, respectively);

3) Ronald Langacker's well-known definition: metonymy is the best entering point into a topic of discussion, a salient and easily coded (source) entity, the reference point that automatically evokes another (target) entity that is of less interest or harder to recall.

Proceeding from these and other theoretical directives, Feyaerts and Brône analyze some German phraseologisms that are, in rhetorical terms, metonymic hyperboles. In the case of humorous metonymies, the prototypical, default process of understanding is interfered, as the reference points are marked and non-salient, and reference point structures deformed. On the other hand, the processing difficulties cannot be too great either, as the joke must nevertheless, in the end, be understood. Therefore Feyaerts and Brône speak of balanced processing difficulty. The difficulty is, in principle, measurable via (or correlated with) the length of the causal chain, i.e. the number of causal 'steps', or 'moves', that are necessary to reach the target concept that the metonymy is to stand for. For example, in the case of the expression Bei deiner Geburt ist wohl etwas Dreck ins Hirn geraten, the alleged length of the causal chain is only one step. The phrase Als dein Vater dich gesehen hat, hat er doch den Storch erschossen, on the contrary, requires the building up of two causal chains embedded in each other, roughly in the following way: 'If the child is ugly, then the father (if he happens to meet the stork) will shoot the stork (because it is guilty of supplying a child of such low quality)'. There are phrases with even more complicated structures, like Du hast wohl als 
Kind einen Schlag auf den Kopf bekommen? Some authors consider such 'humansomatic' figures to be metaphors, whereas others (obviously including Feyaerts and Brône) qualify them as metonymies. Nevertheless, Feyaerts and Brône schematize the 'hit head' also as DAMAGED CONTAINER, but in the current cognitive linguistic theory CONTAINER has become a byword for conceptual me ta phor, not metonymy.

Intuitively, it seems appropriate to think that metonymic utterances of different semantic complexity also need a different amount of 'mental work' to decode them. However, it is hard to believe that this amount could be measured solely via discretely numerable causal steps. Further, the idea of balanced processing difficulty hardly aims to include a tacit implication that the longer the journey from the 'lexical surface' of a metonymy to its actual sense, the funnier the 'mental output' (though it could be considered a hypothesis worth testing), or could a long journey through the jungle of pragmatic inferences, blended mental spaces, maxim violations and the like result in something other than humour?

The phraseological character of empirical texts nevertheless raises a puzzling problem. Unlike in the experimental analyses of various kinds of figurative speech (see e.g. Giora and Fein 1999, Nippold et al. 2000, Brisard et al. 2001, Nippold andTaylor 2002, and many others), in humour research the familiarity / novelty of testable and analyzable items has rarely become a special problem. That may regrettably make the results obtained problematic, due to the ultimate sensibility of the joke material in that respect, i.e., the widely known fact that the punchlined joke forfeits its funniness and enjoyment right after the first hearing.

Due to their continuous reiteration, fixed expressions (idioms, proverbs etc.) are destined to lose, their initial figurative freshness, to die, petrify, entrench themselves in linguistic polysemy. When idioms are researched as hu morous items, the problem becomes particularly topical. The 'awakening' of metaphors, idioms, and the 'decomposing' of compound words (via translating or otherwise) are largely exploited techniques of humour-making (to remember, e.g. the now famous Internet site "Swedish idioms in painfully literal translation", http://home.swipnet.se/ w-52132/te3a/jokes/idiom.html).

In painfully literal translation, the Estonian idiom Tal läks kops üle maksa sounds something like 'His lung crossed went over his liver', which should be irresistibly funny, but in actual use it just means 'he got angry' and nothing else. So, one thing is to try to analyze such units in their restored etymological freshness (as happens in a child's language acquisition), where the supposed difficulties of analytical processing should be enormous, if not insuperable, and quite another, to verbally describe the slight halo of humorous 'ancient glory' surrounding the meaning 'got angry' in practical communication.

Brône and Feyaerts (2004) also analyze some humorous stories and cartoons in the same metonymical spirit and conclude that many humorous items can be explained through prototypicality, salience and markedness that is they do not require a substantial departure from the linguistic level of analysis. Yet the 
approach, as a whole, reminds one of the analysis of metonymy as such rather than analysis of humour, that is, retranslation of many concepts known already from IRT, SSTH, GTVH or elsewhere to terminology used by Langacker, Croft, Giora etc. On the other hand, though, the foregrounding of metonymy as an essential conceptual tool of humour-making is undoubtedly innovative, welcome and valuable, and can eventually invalidate some components of script-based theories, because metonymy is not a between-domain or between-script relation/operation.

\subsubsection{Hopes based on blending}

The model of metaphor in cognitive linguistics has undergone three basic stages:

1) it is considered to be a direct projection from the source to the target;

2) the third, generic level schema is added (for the first time, perhaps, in Lakoff and Turner 1989);

3 ) in the conceptual integration theory (see e.g. Fauconnier and Turner 1994, Turner and Fauconnier 1995, and numerous later writings) the fourth element, blend, is added, and schemas are replaced with mental spaces.

Introduction of the blending component was obviously motivated by two aims:

1) to make the model reflect online processes of understanding and using metaphors in actual communication (see e.g. Katz et al. 1998: 163);

2) to distinguish more clearly the 'domain-bound' and 'propositional' aspects of metaphor, to relate purely cognitive aspects of metaphor (embodiment, conceptuality) with their linguistic manifestations, which were regarded as quite irrelevant in the former Lakoffian theory.

Indeed, although the lower strata of the world of blends are allegedly populated by very elementary beings, like the brown cow or the blue cup, blends quite obviously appear to have a strong natural capacity to feed fantasy and produce humour. Grotesque infernal impressions evoked by the images of the Grim Reaper or Bertrand de Born In Dante's Inferno are not very distant from the outer borders of black humour. Counterfactuals, like If Bill Clinton were the Titanic, the iceberg would sink undoubtedly belong to humour, as numerous proverbs of the same form, e.g. Estonian Oleks seal kü̈̈ned, ta läheks puu otsa (If a pig had nails, it would climb a tree); Oleks tädil till, oleks onu (If auntie had a wee-wee, she would be an uncle); Oleks see koer mitte sitale läinud, ta oleks jänese kätte saanud (If the dog hadn't gone to shit, it would have caught the hare).

Seana Coulson has tested specimens of numerous kinds of human language and verbal and non-verbal creativity (like ordinary context-bound speech, metaphors and other figurative speech, humorous 'one-liners' and longer texts, cartoons, etc.) against practically all of the methods ever invented in cognitive linguistics, psycholinguistics, psychology and neuroscience (see e.g. 1996, 1997: 2001 and many later). In the article What's so funny (Coulson, in print), she analyzes four cartoons about Bill Clinton, including the following. 


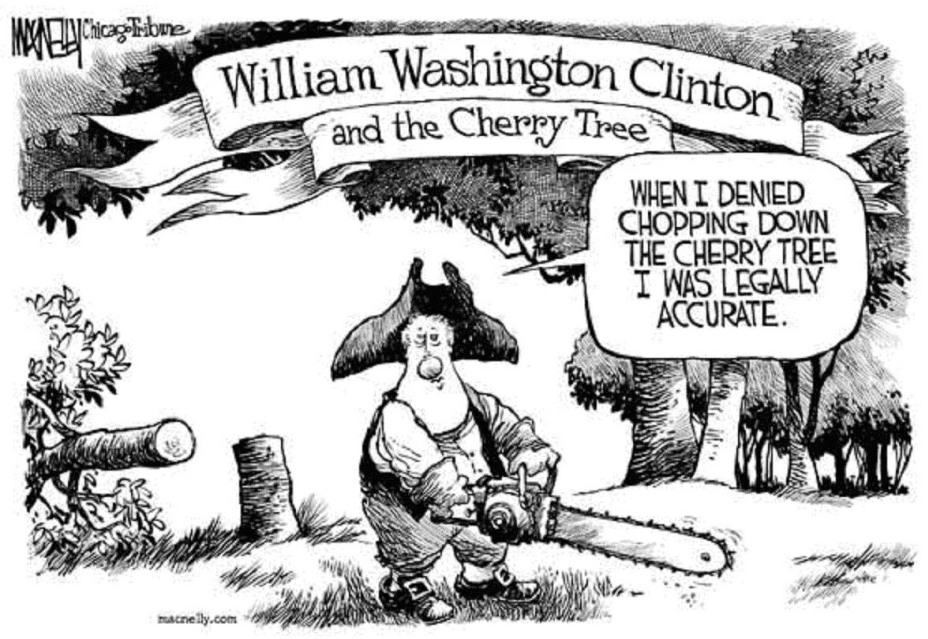

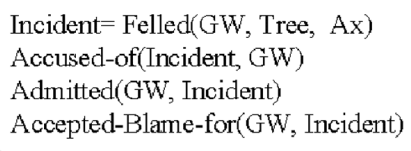

Washington Input
Incident $=$ Sex(BC, Lewinsky)

Accused-of(Incident, BC)

Denied(BC, Incident)

Denied-Blame-for( $\mathrm{BC}$, Incident)

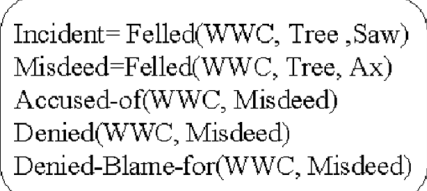

Blend

Already the caption of the cartoon by Jeff MacNelly, William Washington Clinton (quoted from: http://cogsci.ucsd.edu/\%7Ecoulson/funstuff/funny.html), primes its blended character: Bill Clinton's real middle name is not Washington, but Jefferson, the surname of another former U.S. president. Inputs of the cartoon are life episodes of two American presidents, Washington and Clinton:

1) the (allegedly apocryphal) story about Washington: “... when he was a boy, he chopped down a cherry tree in his father's farm. When Washington's father discovered what had happened, he went, furiously, to his family and demanded to know who had chopped down the tree. Knowing that he would likely receive a spanking for his efforts, Washington stood up and said, "I cannot tell a lie. It was I who chopped down the cherry tree"';

2) reference to Clinton's sex scandal with Monica Lewinsky where he initially denied that he had had a sexual relationship with Lewinsky, but later, however, 
"admitted he had indeed had a relationship with Lewinsky that was "not appropriate', but asserted that statements he had made about the matter in the course of a sexual harassment suit filed by Paula Jones had been 'legally accurate'".

The schematized inputs (see above) include the basic elements of both stories, in the form of arguments and predicates: Incident; Accused-of; Admitted / Denied; Blame-for. The blending space includes elements of both inputs, and additionally also new, emergent elements. When 'incident' is tacitly equated with 'misdeed' in inputs, and the agent was blamed for the 'incident', then 'incident' and 'misdeed' are separated in the blending space (that ironically reflects Clinton's state of mind).

Apart from name, the other elements of the cartoon are also blended: the man is holding a modern chainsaw in his hand, not an axe; his face looks like Clinton's, but he is dressed in Colonial garb.

Cartoons and verbal texts are also analyzed in a similar blending manner in Feyaerts and Brône (2002) and Kyratzis (2003). Blend-oriented analyses are fascinating to read, but as the conceptual integration theory as such is an ultimately universal and comprehensive 'theory of everything' (cf. also Gibbs 2000), the analyses that have been performed so far do not aim to tell us more exactly which blends do result in humour and which ones do not.

\section{Joke versus metaphor}

I do not know who invented the maxim "The target comes first and the source comes second" which Mark Turner (e.g. 1991: 144) and others have cited. I also do not remember when it suddenly occurred to me that the question "Which of them wins?" might be also reasonable to ask. Then I learned from Attardo (1994: 138) that the question had already been asked about puns by Pierre Guiraud, but left without a definite answer. Giora (1991:479-481) observes analogous competing readings of classical punning pictures. Then I tried to answer the question for metaphors and jokes on my own, and got: "In metaphors the target wins, but in jokes the source". As it is problematic which of the joke scripts should be treated as the target and which as the source, I cautiously shaped my maxim into a more watertight form: "In metaphors the first isotopy wins, in jokes the second". I have not met anything put thus simplistically elsewhere, but I am almost certain that "the answer is out there". I refer to or quote below some more sophisticated analogues from humour research.

1. If I understood Hillson and Martin (1994) correctly, their experiments with artificial metaphors and jokes seem to show that both of them were appreciated as 'optimally good' (the aptest / funniest) when they fulfilled the two related domainbound requirements of Tourangeau and Sternberg, but for metaphors the criterion of short within-domain distance (that, is, similarity) had relatively greater weight, whereas for jokes the long between-domain distance (that is, incongruity) weighed relatively more. 


\section{From Pollio (1996:248):}

Both metaphor and humor seem to have something to do with split reference; that is, to refer to two different but related images or ideas that take place in proximity to one another. /- - -/ Split reference yields humor if the joined items (or the act joining them) emphasize the boundary of line separating them; split reference yields metaphor if the boundary between the joined items (or the act joining them) is obliterated and the two items fuse to form a single entity.

3a. Giora $(1991: 470,471)$ sets three conditions for different stages of the 'wellformedness of texts in general' and postulates what types of texts conform to which combination.

(5a) obeys the Relevance Requirement; (5b) violates the graded Informativeness Requirement /. - -/ in that it ends in a markedly informative message (the Marked Informativeness Requirement); (5c) causes the reader to perform a linear shift: the reader is made to cancel the first unmarked interpretation upon processing the second marked interpretation (p.470).

A close inspection of the set of rules proposed above reveals that (5a) and (5b) on their own will not suffice as they overgenerate. Apart from jokes, the set of texts or linguistic strings that conform to the Relevance and Marked Informativeness Requirements (5a) and (5b) include metaphors, similes, advertisements; in fact, any text that maintains ambiguity and which I term witty texts. However, unlike witty strings that maintain the ambiguity, the joke is further constrained. Condition (5c) requires that the marked constituent will not be weighed against the unmarked one but erase its impact (p. 471).

3b. Giora 2003:175:

In sum, while jokes and other tropes (irony, metaphor) share similar early processes activating salient meanings initially, they diverge with regard to integration processes. Whereas understanding irony and metaphor involves retention of salient, though contextually incompatible meanings /- - -/, joke interpretation does not. Unlike irony and metaphor, which often use these salient meanings in the processes of their interpretation, such meanings are not instrumental in the comprehension of many jokes and may even get in the way. They are, therefore, discarded, at least momentarily. More research is required to shed light on the issues discussed here.

Thus, a (fresh) metaphor crosses the border, reaches the obstacle, backtracks to the left, looks around, returns to the right, takes something along and returns to the left; joke crosses the border, reaches the obstacle, backtracks to the left, looks around, takes something along, returns to the right and remains.

Be they worded rudely or finely, technical rules of this kind certainly have quite a narrow area of applicability, as they presume that 'the target comes first', i.e., the first step of reading or hearing goes 'from left to right'. Metaphors can, however, already be somehow embedded in jokes, that is, jokes can be based on the literalizing, extending, twisting or mixing of metaphors (like $A$ virgin forest is one where the hand of man has never set foot in Pollio 1996:232), the 'awakening' of dead metaphors (see e.g. Veale 2003, Veale et al. 2006), the parodizing of proverbs (see, e.g., Mieder and Tóthné Litovkina 1999, Valter and Mokienko 2005). 
Original proverbs are usually deadly serious and didactic, but can sometimes be funny enough, like the Estonian Vaese inimese uhkus on nagu kampsuniga magamine: tõmbad pee peale - pea paljas, tõmbad pea peale - pee paljas (Poor man's pride is like sleeping in a sweater - you pull it over your bum and your head is bare; you pull it over your head and your bum is bare) or Kange situb kannad täis playing with two meanings of kange, 'stiff' and 'stubborn, obstinate' (A stiff / stubborn person will shit on his heels).

The syntactic form of a sentence-long or clause-long text does not determine its funniness or unfunniness. Mark Turner's notorious XYZ-structures (see e.g. Turner 1987, 1991:183-215, 1996:104-108, 1998:52-55, Fauconnier and Turner 2002:142 ff., cf. also above about ABC-structures in Hillson and Martin 1994) are close relatives of Aristotle's fourth kind of metaphor (see above at the beginning), they are often quoted as specimens of blends and also very productive in proverbs and aphorisms. Some of them are (or include), occasionally, conventional unfunny metaphors, or fresh unfunny metaphors, or funny non-metaphors, or otherwise. For example, Cheese - milk's leap toward immortality (Turner 1991:203, from Clifton Fadiman) seems to me to be witty, as well as ironic and funny.

Another good example of the kind is the hyperbolic $X$ is so $Y$ that $Z$ structure which Bergen and Binsted (2003) have treated as humour, whose folkloric-phraseologic representatives the Finnish folklorist Anna-Leena Kuusi (1971) has termed consecutive phrases and whose degree of funniness can vary from zero to infinity.

The same holds for similes that constitute the largest subcategory of fixed expressions in most languages. On the lowest end of their funniness scale stand trivialities like cold as ice, hot as fire, white as snow, black as coal, etc., which not only do not reveal any shade of humour, but have completely worn out any figurativeness of their vehicles, coming to function just as hyperboles meaning 'very'. On the highest end, there are similes whose vehicles represent not single words or syntagms, but various bizarre, fantastic, grotesquely funny scenes and situations, like the following Estonian items (see also Õim 2003:60-64):

hädas nagu koer kolmanda julga peal (troubled like a dog on its third turd);

nagu lammas situb kobrulehe peale (like a sheep shitting on a burdock leaf 'about fuzzy, mumbling pronunciation');

edeneb nagu koeral sibulasöömine (successful as a dog eating onions);

opeta nagu oma last leede sitale (like teaching one's own child to shit in the fireplace).

The vehicle itself is composed of absurdly incongruous elements without any resolution: nobody counts dog turds, nor trains children to shit in the fireplace, it is hard to conceive a motivation for a dog to eat onions, and the above-mentioned relationship between sheep and burdocks seems extremely random. Õim's monograph neatly corroborates Giora's statements about the salience / informativeness and unmarkedness / markedness relationships of 'well-formed' texts, but also shows Estonian similes to be extraordinarily diverse material in these respects, even perhaps exceeding the gradient limits postulated by Giora and others. 
Nevertheless, the question remains as to what the increasing complexity of conceptual structure of the 'well-formed' texts could, finally, achieve. One (intermediate?) stage is obviously humour. But it is already supposed there will never be any 'absolute entropy'. It is already stated that even the shortest casually generated and preselected nonsensical word strings can be divided into simply nonsense and funny nonsense. Juri Lotman (1970:250) claims that the best poetical metaphors are precisely those which outside of their concrete context qualify as nonsense. Samuel Levin (1977:128-134), in turn, finds that there is no reason at all to speak of poetical metaphors, because poems build up their own individual possible worlds, inside of which metaphors do not need any special construal. Jaan Undusk, the well-known Estonian theorist of literature, culture and rhetoric, is convinced that oxymoron, the condensed unity of sense and nonsense, is the deepest basis and origin of all poetical and rhetorical creation.

\section{In lieu of a conclusion: Back to Methuselah?}

Our brief observation can be summarized in the four following (mostly sceptical) points:

1. The theory of humour and the cognitivistic theory of figurative speech have begun to notice and reach out towards each other.

2. In the process of approximation, cognitive linguists have played a more active role, sometimes too excessively denying the identity and specificity of humour.

3. It is still too early to speak of clear-cut criteria for distinguishing between jokes and metaphor, let alone humour and figurative speech.

4. It is difficult to objectively evaluate the current state of Attardo's humour theory and the cognitivistic (originally Lakoffian) theory of figurative language and forecast their sustainability.

Considering the existence of such borderline phenomena as puns, oxymorons, zeugmas, spoonerisms, malapropisms, irony, allegory, etc., as well as observations made by Giora and others, it is perhaps reasonable to think that the lines separating humour and figurative speech in general are not distinctly clear and discrete, but multivalently continuous and gradual.

Perhaps cognitive theorists of figurative language and humour should strive for closer integration with researchers of the cultural and social aspects of human communication, for the greater 'ecological validity' of the results they are obtaining. It is one thing to test the psychological effects of casual word combinations for groups of gender balanced right-handed students of psychology, and quite another to turn to stores of culturally 'ready-made' materials. Taken in this perspective, both rhetoric and humour have long (and different) historical pedigrees. Nature and culture seem to have long collaborated to set certain general (and different again) restrictions, or streambeds, for both conventional metaphors and jokes. The main axis of metaphorical traffic seems to be human / non- 
human', rendering all the rest irrelevant and thus producing two basic types of metaphors - anthropomorphic and deanthropomorphic. It is certainly not by chance, either, that we can distinguish three main types of humour - sexual (and scatological), ethnic and political, all the rest being relatively irrelevant.

Searching for better criteria to distinguish humour from figurativeness and funniness from seriousness, it might perhaps be good to look back to former theories of superiority/disparagement and relaxation/relief that have been declared tacitly and utterly obsolete, often for outside reasons like political correctness and related forms of social hypocrisy. However, quite recent psychological observations appear to confirm that items of disparaging humour tend to get the highest ratings for funniness (Graesser et al. 1989), and disparaging metaphors are perceived to be funnier than others (Mio and Graesser 1991). David Ritchie (2005) calls upon researchers to rediscover broader social backgrounds from behind frame-shifting and other purely cognitive constructs. Surprisingly enough, Tony Veale (2004) also finds that the humorous effect arises not because jokes, thanks to their structural properties, force their resolutions on listeners, but because the listener as a social being is predisposed, attuned to find humour wherever possible, and therefore experiencing humour is a two-way, collaborative process. Veale refers to this set of deeper drives as social logic: “... a humor theory must not look to incongruities, but provide a social explanation for why we enjoy insulting others and why a feeling of social intimacy can arise when this insult is licensed by the cooperative principle of joke-telling" (p. 424), or further: "What is needed is not a logical mechanism as such, or a logic of oppositions, but a social logic that allows a theory to ground the interpretation in the specific concerns and prejudices of the listener as a social agent" (pp. 424-425).

The punchlined joke is the basic form of contemporary humour; the joke generally has a target, that is, the object to whom the joke is critically disposed. The joke does have the function of a social weapon, however Marxist that might sound, and it also has the function of a taboo-breaker, however Freudian that might sound. It is not by chance that political, social, ethnic and obscene (erotic or scatological) themes are statistically prevalent in contemporary jokes. It is not by chance, either, that the period of Brezhnev's rule (and particularly the last part thereof) was a golden era of joke-making in the former USSR and perhaps in the countries of the Socialist bloc in general. It is not by chance that, despite the proliferating cult of sex, joke tradition in contemporary welfare societies is undergoing a rapid degeneration, and the same trend is also becoming more and more apparent in the post-socialist countries, where neo-capitalism has not evolved forms wild enough to guarantee the sustainability of the joke tradition.

\section{Acknowledgements}

This study was supported by the Estonian Science Foundation Grant No. 6759. 
Address:
Arvo Krikmann
Department of Folklore
Estonian Literary Museum
Vanemuise 42
51003 Tartu, Estonia

Tel.: +37253416520

E-mail: kriku@folklore.ee, krikud@hot.ee

\section{References}

Aristotle (2004) Poetics. Translated by S. H. Butcher. eBooks@ Adelaide http://www.mv.helsinki.fi/ home/tkannist/E-texts/Aristotle/Poetics/

Attardo, Salvatore (1993) "Violation of conversational maxims and cooperation: the case of jokes". Journal of Pragmatics 19, 6, 537-558.

Attardo, Salvatore (1994) Linguistic theories of humor. Berlin and New York: Mouton de Gruyter.

Attardo, Salvatore (1997) "The semantic foundations of cognitive theories of humor". HUMOR: International Journal of Humor Research 10, 4, 395-420.

Attardo, Salvatore and Victor Raskin (1991) "Script theory revis(it)ed: joke similarity and joke representation model". HUMOR: International Journal of Humor Research 4, 3-4, 293-347.

Attardo, Salvatore, Donalee Hughes Attardo, Paul Baltes, and Marnie Jo Petray (1994) "The linear organization of jokes: analysis of two thousand texts". HUMOR: International Journal of Humor Research 7, 1, 27-54.

Attardo, Salvatore, Christian F. Hempelmann, and Sara Di Maio (2002) "Script oppositions and logical mechanisms: modeling incongruities and their resolutions". HUMOR: International Journal of Humor Research 15, 1, 3-46.

Attardo, Salvatore (2006) "Cognitive linguistics and humor". HUMOR: International Journal of Humor Research 19, 3, 341-362.

Barcelona, Antonio (2000) "On the plausibility of claiming a metonymic motivation for conceptual metaphor". In Metaphor and metonymy at the crossroads: a cognitive perspective, 31-58. Antonio Barcelona, ed. Berlin and New York: Mouton de Gruyter.

Barcelona, Antonio (2003) "The case for a metonymic basis of pragmatic inferencing: evidence from jokes and funny anecdotes". In Metonymy and pragmatic inferencing, 81-102. Klaus-Uwe Panther and Linda L. Thornburg, eds. Amsterdam and Philadelphia: John Benjamins Publishing Company.

Becker, Angela H. (1997) "Emergent and common features influence metaphor interpretation". Metaphor and Symbol 12, 4, 243-259.

Bergen, Benjamin and Kim Binsted (2003) "The cognitive linguistics of scalar humor". In Language, culture, and mind, 79-92. Michel Archard and Suzanne Kemmer, eds. Stanford: CSLI Publications.

Black, Max (1962) Models and metaphors. Ithaca and New York: Cornell University Press.

Bowdle, Brian F. and Dedre Gentner (2005) "The career of metaphor". Psychological Review 112, 1, 193-210.

Brisard, Frank, Steven Frisson, and Dominiek Sandra (2001) "Processing unfamiliar metaphors in a self-paced reading task". Metaphor and Symbol 16, 1-2, 87-108.

Brône, Geert and Kurt Feyaerts (2003) "The cognitive linguistics of incongruity resolution: Marked reference-point structures in humor". [8th International Cognitive Linguistics Conference: July 20-25, 2003, University of La Rioja, Spain. Theme session: Cognitive-Linguistic Approaches to Humour] http://wwwling.arts.kuleuven.ac.be/iclc/Papers/BroneFeyaerts.pdf

Brône, Geert and Kurt Feyaerts (2004) "Assessing the SSTH and GTVH: a view from cognitive linguistics". HUMOR: International Journal of Humor Research 17, 4, 361-372.

Brône, Gert, Kurt Feyaerts, and Tony Veale (2006). "Introduction: cognitive linguistic approaches to humor”. HUMOR: International Journal of Humor Research 19, 3, 203-228. 
Coulson, Seana (1996) "The Menendez Brothers Virus: analogical mapping in blended spaces". In Conceptual structure, discourse, and language, 67-81. Adele Goldberg ed. Palo Alto, CA: CSLI.

Coulson, Seana (1997) Semantic leaps: the role of frame-shifting and conceptual blending in meaning construction. Unpublished doctoral dissertation. University of California, San Diego.

Coulson, Seana (2001) Semantic leaps: frame-shifting and conceptual blending in meaning construction. Cambridge: Cambridge University Press.

Coulson, Seana (in print). "What's so funny: conceptual blending in humorous examples". In The poetics of cognition: studies of cognitive linguistics and the verbal arts. V. Herman, ed. Cambridge: Cambridge University Press. Available from the web address: http://cogsci.ucsd.edu/\%7Ecoulson/funstuff/funny.html

Coulson, Seana and Marta Kutas (1998) Frame-shifting and sentential integration. Technical Report CogSci. UCSD-98.03. October, 1998. Department of Cognitive Science, UCSD, San Diego, CA, 92093-0515.

Croft, William and D. Alan Cruse (2004) Cognitive linguistics. Cambridge: Cambridge University Press.

Dirven, René (2002 [1993]) "Metonymy and metaphor: different mental strategies of conceptualisation". In Metaphor and metonymy in comparison and contrast, 75-111. René Dirven and Ralf Pörings, eds. Berlin and New York: Mouton de Gruyter.

Douglass, David (2000) "Issues in the use of I. A. Richards' tenor-vehicle model of metaphor". Western Journal of Communication 64, 4, 405-424.

Fauconnier, Gilles and Mark Turner (1994) Conceptual projection and middle spaces. Department of Cognitive Science Technical Report 9401. San Diego: University of California, San Diego http://www.cogsci.ucsd.edu/research/files/technical/9401.pdf

Fauconnier, Gilles and Mark Turner (2002) The way we think: conceptual blending and the mind's hidden complexities. Basic Books.

Feyaerts, Kurt and Geert Brône (2002) "Humor through 'double grounding': structural interaction of optimality principles". The way we think: a research symposium on conceptual integration and the nature and origin of cognitively modern human beings (Odense, Denmark, August 19-23, 2002). Odense Working Papers in Language and Communication, vol. I-II, 313-336. Anders Hougaard and Steffen Nordaal eds. Odense: Odense University, Institute of Language and Communication http://eric.ed.gov/ERICDocs/data/ericdocs2sql/ content_storage_01/0000019b/80/1a/bb/75.pdf

Gentner, Dedre and Jose Medina (1997) "Comparison and the development of cognition and language". Cognitive Studies: Bulletin of the Japanese Cognitive Science Society 4, 1, 112 149.

Gentner, Dedre and Jose Medina (1998) "Similarity and the development of rules". Cognition 65, 23, 263-297.

Gentner, Dedre and Laura L. Namy (1999) "Comparison in the development of categories". Cognitive Development 14, 4, 487-513.

Gentner, Dedre and Phillip Wolff (2000) "Metaphor and knowledge change". In Cognitive dynamics: conceptual change in humans and machines, 295-342. E. Dietrich and A. Markman, eds. Mahwah, NJ: Lawrence Erlbaum Assoc.

Gentner, Dedre, Brian F. Bowdle, Phillip Wolff, and Consuelo Boronat (2001) "Metaphor is like analogy". In The analogical mind: perspectives from cognitive science, 199-253. Dedre Gentner, Keith J. Holyoak, and Boicho N. Kokinov, eds. Cambridge, Mass. and London, England: The MIT Press.

Gibbs, Raymond W., Jun. (1994) The poetics of mind: figurative thought, language, and understanding. New York and Melbourne: Cambridge University Press.

Gibbs, Raymond W., Jun. (2000) "Making good psychology out of blending theory". Cognitive Linguistics 11, 3-4, 347-358.

Gineste, Marie-Dominique, Bipin Indurkhya, and Véronique Scart (2000) "Emergence of features in metaphor comprehension". Metaphor and Symbol 15, 3, 117-135. 
Giora, Rachel (1991) "On the cognitive aspects of the joke”. Journal of Pragmatics 16, 5, 465-485.

Giora, Rachel (2003) On our mind: salience, context, and figurative language. Oxford, New York, Auckland, Bangkok, etc.: Oxford University Press.

Giora, Rachel and Ofen Fein (1999) "On understanding familiar and less-familiar figurative language". Journal of Pragmatics 31, 12, 1601-1618.

Glucksberg, Sam (2001) Understanding figurative language: from metaphors to idioms. Oxford and New York: Oxford University Press.

Graesser, Arthur C., Debra L. Long, and Jeffery S. Mio. (1989) "What are the cognitive and conceptual components of huomorous text?" Poetics 18, 1-2, 143-163.

Greimas, A. J. (1971 [1966]) Strukturale Semantik. Methodologische Untersuchungen. Braunschweig: Friedr. Vieweg + Sohn.

Grice, Paul (1991 [1989]) Studies in the way of words. Cambridge, Mass. and London, England: Harvard University Press.

Hillson, Tim R. and Rod A. Martin (1994) "What's so funny about that? The domain-interaction approach as a model of incongruity and resolution in humor". Motivation and Emotion 18, 1, $1-29$.

Indurkhya, Bipin (1992) Metaphor and cognition: an interactionist approach. Dordrecht, Boston, and London: Kluwer Academic Publishers.

Jakobson, Roman (1956) "The metaphoric and metonymic poles". In R. Jakobson and M. Halle. Fundamentals of language. 2nd ed., 76-82. Hague and Paris: Mouton.

Johnson, Mark (1987) The body in the mind: the bodily basis of meaning, imagination, and reason. Chicago and London: The University of Chicago Press.

Johnson, Mark (1993) Moral imagination: implications of cognitive science in ethics. Chicago and London: The University of Chicago Press.

Katz, Albert N., Cristina Cacciari, Raymond W. Gibbs Jr., and Mark Turner (1998) Figurative language and thought. Oxford and New York: Oxford University Press.

Koestler, Arthur (1964) The act of creation. London: Hutchinson \& Co.

Kövecses, Zoltán (1986) Metaphors of anger, pride, and love: a lexical approach to the study of concepts. Amsterdam: John Benjamins.

Kövecses, Zoltán (1988) The language of love: the semantics of passion in conversational English. Lewisburg: Bucknell University Press.

Kövecses, Zoltán (1990) Emotion concepts. New York: Springer Verlag.

Krikmann, Arvo (2007) "Contemporary linguistic theories of humour". Folklore: Electronic Journal of Folklore 33, 27-57 http://www.folklore.ee/folklore/vol33/kriku.pdf

Kyratzis, Sakis (2003) "Laughing metaphorically: metaphor and humour in discourse". [8th International Cognitive Linguistics Conference: July 20-25, 2003, University of La Rioja, Spain. Theme session: Cognitive-Linguistic Approaches to Humour] http:// wwwling.arts.kuleuven.ac.be/iclc/Papers/Kyratzis.pdf

Kuusi, Anna-Leena (1971) Johdatusta suomen kielen fraseologiaan. [Introduction to Finnish Phraseology.] Helsinki: SKS.

Lakoff, George (1987) Women, fire, and dangerous things: what categories reveal about the mind. Chicago and London: Chicago University Press.

Lakoff, George and Mark Johnson (1980) Metaphors we live by. Chicago and London: Chicago University Press.

Lakoff, George and Mark Turner (1989) More than cool reason: a field guide to poetic metaphor. Chicago and London: The University of Chicago Press.

Levin, Samuel R. (1977) The semantics of metaphor. Baltimore and London: The John Hopkins University Press.

Lotman, Juri (1970) Struktura xudožestvennogo teksta. Moscow: Nauka.

Markman, Arthur B. and Dedre Gentner (2000) "Structure mapping in the comparison process". American Journal of Psychology 113, 4, 501-538.

Mieder, Wolfgang and Anna Tóthné Litovkina (1999) Twisted wisdom: modern anti-proverbs. Burlington: The University of Vermont. 
Mio, Jeffery Scott and Arthur C. Graesser (1991) "Humor, language, and metaphor". Metaphor and Symbolic Activity 6, 2, 87-102.

Morreall, John, ed. (1987) The philosophy of laughter and humor. Albany, NY: State University of New York Press.

Nippold, Marylin, Melissa M. Allen, and Dixon I. Kirsch (2000) "How adolescents comprehend unfamiliar proverbs: the role of top-down and bottom-up processes". Journal of Speech, Language, and Hearing Research 43, 3, 621-630.

Nippold, Marylin A. and Catherine L. Taylor (2002) "Judgments of idiom familiarity and transparency: a comparison of children and adolescents". Journal of Speech, Language, and Hearing Research 45, 2, 384-391.

Õim, Katre (2003) Võrdluste struktuurist ja kujundisemantikast. [The structure and figurative semantics of similes.]. (Reetor, 2.) Tartu: Eesti Kirjandusmuuseum.

Ortony, Andrew (1979) "The role of similarity in similes and metaphors". In Metaphor and thought, 186-201. Andrew Ortony, ed. Cambridge, London, New York, and Melbourne: Cambridge University Press.

Peirsman, Yves and Dirk Geeraerts (2006) "Metonymy as a prototypical category". Cognitive Linguistics 17, 3, 269-316.

Pollio, Howard R. (1996) "Boundaries in humor and metaphor". In Metaphor: implications and applications, 231-253. Jeffrey Scott Mio and Albert N. Katz, eds. Mahwah, New Jersey: Laurence Erlbaum Associates.

Radden, Günther and Zoltán Kövecses (1999) “Towards a theory of metonymy”. In Metonymy in language and thought, 17-59. Klaus-Uwe Panther and Günther Radden, eds. Amsterdam and Philadelphia: John Benjamins Publishing Company.

Raskin, Victor (1985) Semantic mechanisms of humor. Dordrecht, Boston, and Lancaster: D. Reidel Publishing Company.

Richards, Ivor Armstrong (1936) The philosophy of rhetoric. London, Oxford, and New York: Oxford University Press.

Ritchie, David (2005) "Frame-shifting in humor and irony". Metaphor and Symbol 20, 4, 275-294.

Ritchie, Graeme (2004) The linguistic analysis of jokes. London and New York: Routledge.

Ruiz de Mendoza Ibañes, Francisco José and Lorena Pèrez Hernández (2001) "Metonymy and the grammar: motivation, constraints and interaction". Language and Communication 21, 4, 321-357.

Searle John R. (1979) "Metaphor". In Metaphor and thought, 92-123. Andrew Ortony, ed. Cambridge, London, New York, and Melbourne: Cambridge University Press.

Shultz, Thomas R. (1996 [1976]) “A cognitive-developmental analysis of humour”. In Humor and laughter: theory, research, and applications, 11-36. Antony J. Chapman and Hugh D. Foot, eds. With a new introduction by Peter Derks. New Brunswick and London: Transaction Publishers.

Sperber, Dan and Deirdre Wilson (1981) "Irony and the use-mention distinction". In Radical pragmatics, 295-318. Peter Cole, ed. New York: Academic Press.

Steen, Gerard J. (1994) Understanding metaphor in literature: an empirical approach. Harlow: Longman.

Suls, Jerry M. (1972) "A two-stage model for the appreciation of jokes and cartoons: an informationprocessing analysis". In The psychology of humor: theoretical perspectives and empirical issues, 81-100. Jeffrey H. Goldstein and Paul E. McGhee. New York and London: Academic Press.

Sweetser, Eve (1990) From etymology to pragmatics: the mind-body metaphor in semantic structure and semantic change. Cambridge: Cambridge University Press.

Tourangeau, Roger and Robert J. Sternberg (1981) "Aptness in metaphor". Cognitive Psychology 13, $1,27-55$.

Tourangeau, Roger and Robert J. Sternberg (1982) "Understanding and appreciating metaphors". Cognition 11, 3, 203-244.

Turner, Mark (1987) Death is the mother of beauty: mind, metaphor, criticism. Chicago: Chicago University Press. 
Turner, Mark (1991) Reading minds: the study of English in the age of cognitive science. Princeton, N.J.: Princeton University Press.

Turner, Mark (1996) The literary mind: the origins of thought and language. Oxford and New York: Oxford University Press.

Turner, Mark (1998) "Figure". In A. N. Katz, C. Cacciari, R. W. Gibbs Jr., and M. Turner, Figurative language and thought, 44-87. Oxford and New York: Oxford University Press.

Turner, Mark and Gilles Fauconnier (1995) "Conceptual integration and formal expression". Metaphor and Symbolic Activity 10, 3, 183-204.

Tversky, Amos (1977) "Features of similarity". Psychological Review 84, 4, 327-352.

Utsumi, Akira (2005) "The role of feature emergence in metaphor appreciation". Metaphor and Symbol 20, 3, 151-172.

Utsumi, Akira (2006a) "Computational exploration of metaphor comprehension processes". Proceedings of the Cognitive Science Society (CogSci2006), 2281-2286 http:// www.utm.se.uec.ac.jp/ utsumi/paper/cogsci2006-utsumi.pdf

Utsumi, Akira (2006b) "A cognitive approach to poetic effects of rhetorical figures: toward a unified theory of cognitive rhetoric". Proceedings of the 19th Congress of the International Association of Empirical Aesthetics (IAEA2006), 413-417 http://www.utm.se.uec.ac.jp/ utsumi/paper/iaea2006-utsumi.pdf

Valter, Harri and Valeri Mokienko (2005) Antiposlovicy russkogo naroda. Sankt-Peterburg and Moscow: Neva.

Veale, Tony (2003) "Metaphor and metonymy: the cognitive trump-cards of linguistic humour". [Presented as a keynote talk at the ICLC theme session on Cognitive Linguistic Approaches to Humour, as part of the 2003 International Conference on Cognitive Linguistics] http://afflatus.ucd.ie/papers/iclc2003.pdf

Veale, Tony (2004) "Incongruity in humor: root cause or epiphenomenon?". HUMOR: International Journal of Humor Research 17, 4, 419-428.

Veale, Tony, Kurt Feyaerts, and Geert Brône (2006) "The cognitive mechanisms of adversarial humor". HUMOR: International Journal of Humor Research 19, 3, 305-339.

Yamaguchi, Haruhiko (1988) "How to pull strings with words: deceptive violations in the gardenpath joke". Journal of Pragmatics 12, 3, 323-337. 